\title{
Design of a Plant Leaf Area Meter Using PV Cell and Embedded Microcontroller
}

\author{
Dilşad Engin ${ }^{1}$ and Mustafa Engin ${ }^{2}$ \\ ${ }^{1}$ Ege University, Ege Higher Vocational School Control and Automation Technology Department, Bornova, 35100 İzmir, Turkey \\ ${ }^{2}$ Ege University, Ege Higher Vocational School, Department of Electronics Technology, Bornova, 35100 Izmir, Turkey
}

Correspondence should be addressed to Mustafa Engin; mustafa.engin8@gmail.com

Received 2 June 2013; Accepted 6 November 2013

Academic Editor: Aiguo Xu

Copyright (C) 2013 D. Engin and M. Engin. This is an open access article distributed under the Creative Commons Attribution License, which permits unrestricted use, distribution, and reproduction in any medium, provided the original work is properly cited.

\begin{abstract}
This paper presents the development of a solar cell based simple and practical leaf area meter. The system has a silicon solar module which is composed of 6 series connected cells, a light source, and a parabolic reflector with opal glass for diffusing the light. Partial shading effect on PV cell's voltage and current are evaluated with different geometrical shapes for testing the performance of the model, and the resulting equations for voltage and current changes with respect to measured areas are obtained. The measured current has a good correlation: $R^{2}>0.99$ for regularly shaped leaves and $R^{2}>0.95$ for irregularly shaped ones. The resulting voltage and current measurements are then fed to an ARM Cortex M3 core 32-bit LM3S1968 microcontroller via a voltage and current measuring unit. The calculated leaf areas from the obtained area-current relations are shown on an OLED graphics display. The whole system is easy to use and user-friendly. The leaf area measurements are confirmed by comparing the results with measurements of grid counting method.
\end{abstract}

\section{Introduction}

Leaf area measurement is almost an essential aspect in agricultural and biological studies in order to observe the growth and development of plants. Leaf area measurement methods are classified as paper weighing, grid counting, regression equation [1], width and height correlation model $[2,3]$ estimation of leaf area by regression analysis of leaf area versus length and width $[4,5]$, and measuring the leaf's area that is copied onto a paper by a planimeter $[6,7]$. Grid counting method is simple in principle and has a high accuracy; on the other hand it takes time to measure the exact leaf area. The paper-weighing, the so-called gravimetric method is built on the paper weight that is cut exactly in the form of the leaf by tracing the contour and then compared to the dry weight of leaves using predetermined leaf-areato-dry-weight ratios, provides a precise measurement of the leaf area, but in fact it is an inconvenient procedure and not applicable to a large number of leaves. Regression equation method is constituted for a specific plant, though it has restricted application. A portable leaf area meter measures the leaf area with high accuracy, but they are mostly expensive.

Commercial leaf area measuring instruments work in the way that the leaf passes through a light beam via a conveyor belt driven at a constant speed. Leaf area measurement is made on the basis of digital estimation of the intercepted amount of light by the leaf. A semiautomatic leaf-area measuring device which has a feeding mechanism was developed by Murata and Hayashi [8] and since then it found a wide area of utilization.

Following the developments in digital image technology, newer methods are developed where the leaf is scanned and the image is loaded to a personal computer $[9,10]$, digital image acquisition system based on leaf contouring with mouse obtained from a digital camera [11-13], leaf area calculation by image processing methods using a microprocessor or software packages used for numerical computation, modeling and visualization for data analysis [14-18], image analysis of total leaf area by width and height model [19], and measurement of the amount of light interrupted by a leaf 


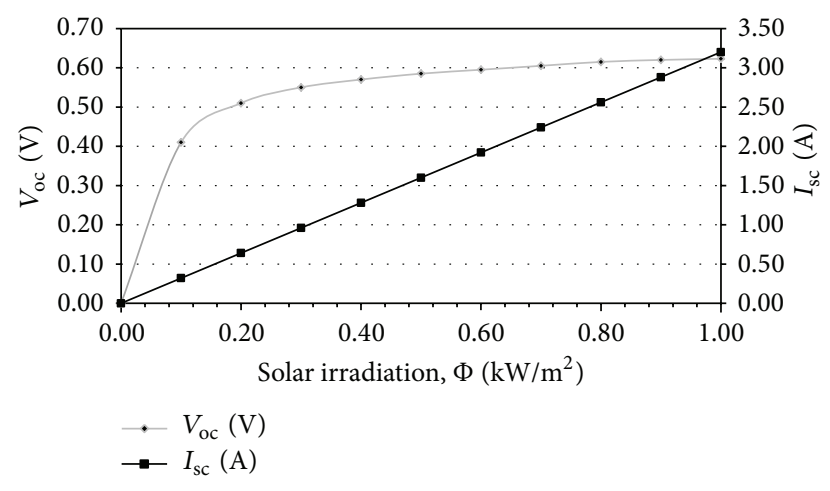

FIGURE 1: $V_{\mathrm{oc}}$ and $I_{\mathrm{sc}}$ variations as a result of changes in radiation.

using a photovoltaic cell [20, 21]. Measurement of leaf area by image processing methods is fast, accurate, and stable, and leaf size, thickness, shape are of no effect, but this method can be neither used without a computer nor at the site [14, 22, 23].

In this study, a leaf area measuring system using a photovoltaic (PV) cell was developed and established. For evaluation of the figure of merit of the PV leaf area meter under test, several geometric shapes of known areas are used. The obtained findings are given in the results section, and the discussion of the outcomes is specified in the succeeding part.

\section{Material and Method}

2.1. PV Module. In this study of leaf area measurement with PV cells, two $7 * 10 \mathrm{~cm}^{2}$ and $5 * 7 \mathrm{~cm}^{2}$ amorphous silicon solar modules which were composed of 6 series connected cells were used. Photovoltaic cells are semiconductor devices that transform light coming from the sun into direct current (DC) electricity. When photons of solar energy hits the surface of a solar cell, the stimulated electrons are broken loose from the atoms in the semiconductor material, resulting in a flow of photocurrent $\left(I_{\mathrm{ph}}\right)$ when the cell is connected to an electrical load $[24,25]$. Photovoltaic cells are connected electrically in series and/or parallel circuits to produce higher voltages and/or currents, whereas photovoltaic modules consist of PV cell circuits connected in series and/or parallel.

The maximum variation by the incident solar irradiation is in solar module's current (Figure 1). Solar module's short circuit current, $I_{\mathrm{sc}}\left(=I_{\mathrm{ph}}\right)$, which is the greatest value of the current produced by a PV cell, is directly proportional with the solar irradiation (1) [25]. Open circuit voltage, $V_{o c}$, which characterizes the voltage drop across the PV cell when the generated current is $I=0$, is a function of $I_{s c}$ (2) [26]:

$$
I_{\mathrm{sc}}=c G_{a}
$$

where $c$ is a constant and $G_{a}$ is solar irradiation in $\mathrm{W} / \mathrm{m}^{2}$ :

$$
V_{\mathrm{oc}}=\frac{m k T_{c}}{e} \ln \left(\frac{I_{\mathrm{sc}}}{I_{0}}\right)=V_{t} \ln \left(\frac{I_{\mathrm{sc}}}{I_{0}}\right),
$$

where $V_{\text {oc }}$ is solar module's open circuit voltage $(\mathrm{V}), m$ is idealizing factor, $e$ is electron charge $\left(1.602 \times 10^{-19} \mathrm{C}\right), k$ is
Boltzmann's gas constant $\left(1.38 \times 10^{-23} \mathrm{~J} / \mathrm{K}\right), T_{c}$ is absolute temperature of the cell $(\mathrm{K}), I_{0}$ is dark saturation current $(\mathrm{mA}), I_{\mathrm{sc}}$ is solar module short circuit current $(\mathrm{mA})$, and $V_{t}$ is thermal voltage.

For a PV cell, both $I_{\mathrm{sc}}$ and $V_{\mathrm{oc}}$ are temperature dependent as given in

$$
\begin{gathered}
V_{\mathrm{oc}}=V_{\mathrm{oc}, 0}+K_{V}\left(T_{c}-T_{0}\right), \\
I_{\mathrm{sc}}=\left(\frac{G_{a}}{G_{a, 0}}\right)\left[I_{\mathrm{sc}, 0}+K_{I}\left(T_{c}-T_{0}\right)\right],
\end{gathered}
$$

where $V_{\mathrm{oc}, 0}$ is the open circuit voltage, $I_{\mathrm{sc}, 0}$ is the short circuit current, $T_{0}$ is the cell temperature under standard test conditions $\left(G_{a, 0}=1000 \mathrm{~W} / \mathrm{m}^{2}, T_{0}=25^{\circ} \mathrm{C}\right)$, and $K_{V}$ and $K_{I}$ are temperature coefficients of open circuit voltage and short circuit current, respectively. For amorphous silicon (a-Si) cells, $K_{I}$ is fairly small [27] which does have slight effect on the current related to the area measurement.

2.2. Experimental Setup. In the experimental setup, $11 \mathrm{~W}$ PL lamp [28] was used as a light source. The choice of this kind of lamp depends on the fact that the light it gives off resembles sunlight and the radiated heat amount is fairly low; thus it almost does not increase the cell temperature. This PL lamp was placed in the focus of a parabolic reflector which was located at the bottom of an opaque case. The stainless steel reflector was curved so as to reflect the light from the light source to the solar module in parallel (Figure 2). The opal glass used for diffusing the parallel reflected light was mounted on top of the case, just beneath the cover, whereas the solar module was placed on the inner cover. The areas to be measured were located on the glass so as that they would be in between this glass and the solar module when the cover was closed (Figure 3 ).

The leaf area measuring method is determined as to send a light beam onto the solar module where the leaf is placed on it, and thereby the solar module is shadowed and the produced current due to this shadowing amount is measured.

As the amount of radiation changes effects solar module's short circuit current foremost, the amount of the incident light on the solar module was reduced by opaque and semitransparent samples of various shapes with known areas and accordingly, current and voltage values were measured and recorded. It is then examined whether the solar module is an appropriate device for leaf area measurement.

For the purpose of leaf area measurement, opaque and semitransparent samples with different geometric shapes were prepared regarding various leaf species of different figures and transparency. ITT Metrics 4.5 digit multimeter with a current resolution of $0.01 \mathrm{~mA}$ was connected to the series-connected solar module for measuring current and voltage values affected by the shadowing of the module by the samples. The short circuit current and the open circuit voltage variations due to the shadowing area of the solar module were measured in order to determine the area of the sample areas.

For the sensing part of the leaf area meter, $7 * 10 \mathrm{~cm}^{2}$ thinfilm amorphous silicon solar module was used. The sample areas of rectangular shape were placed onto the solar module 

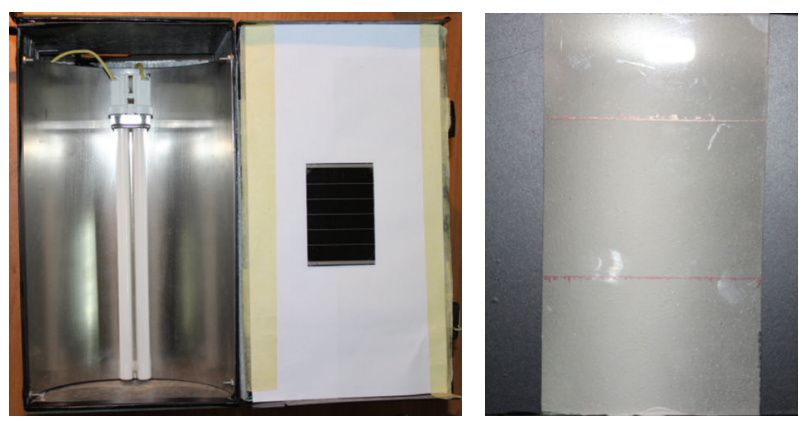

FIGURE 2: Testing apparatus of leaf area measurement showing placement of lamp, parabolic reflector, and solar module.

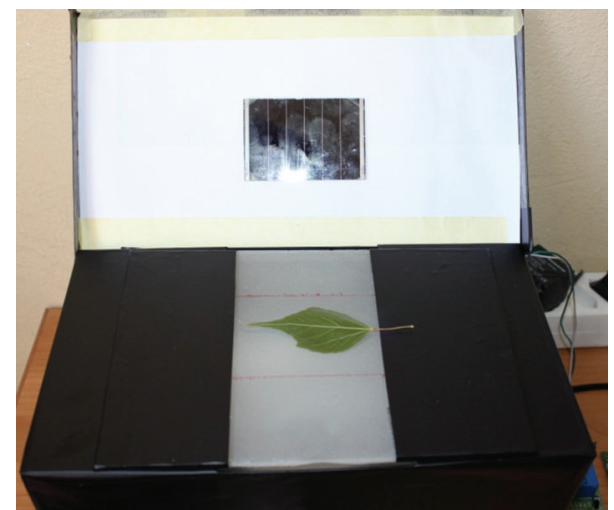

FIGURE 3: The layout of the opal glass used for diffusing the parallel reflected light.

so that their shadowing effect on the solar module's measured current and voltage could be examined. The samples' areas were varying from $10 \%$ to $100 \%$ of the solar module having an equal width with the solar module. The measurements with the same samples were repeated with a $5 * 7 \mathrm{~cm}^{2}$ thin-film solar module of the same properties with the previous one.

Considering that the leaf areas would be of various shapes, six different geometric shapes were used. These sample areas are from $10 \%$ of solar module's area to the extent that the geometric shape and the solar module's physical dimensions allow. In this work, making allowance for the possible different transparencies of the leaves whose areas are to be measured, the sample areas were prepared using opaque carton and semitransparent white paper materials.

For observing the partial shadowing effect on the solar module's current, when one of the cells in a module was totally shadowed by the sample areas with different geometries, it was discovered that there was a sudden decrease in the solar module's current. The shadowing of one of the series connected cells causes low energy input to the cell resulting in a current decrease of that cell and consequently the solar module [29-31].

As the partial shadowing on a module had a nonlinear influence on the output current [32-35], the measurements were repeated by means of shadowing the light source instead. The experimental setup was arranged so that a transparent flat glass was placed on the light source and the opal glass was positioned so as to transmit the incoming light to the solar module by scattering. The incident light amount on the opal glass is changed by the sample areas prepared by opaque carton and semitransparent white paper materials and solar module's short circuit current and open circuit voltage measurements were carried out.

2.3. Measurement and Display Unit. This unit converts current and voltage values to leaf area according to given equation. Measurement and display unit is composed of two circuits. The first one measures PV module open circuit voltage and short circuit current and process them to make suitable for embedded microcontroller inputs. The second one mainly contains embedded microcontroller and OLED display unit. It converts voltage and current signals to the digital form and calculates leaf area. Then it shows the results with the user friendly interfaces.

2.3.1. Current and Voltage Measurements. PV module's current and voltage can be measured using current and voltage sensors. After defining the voltage and current variables, they need amplification or attenuation and filtering to make noiseless and precise measurement. The current measurement section of the circuit translates the current received from the PV module into a small voltage form which will be applied to the analogue to digital converter (ADC) of the microcontroller. This stage consists of a Hall-effect current sensor, amplification, and filter circuits. Hall-effect sensor, LA25-NP [36], exhibits good linearity and is temperature compensated. It also shows high grade performances in terms of accuracy and immunity to noise. Compensated Hall-effect contactless current devices are obtainable for measurements in the range between $\mathrm{mA}$ to $\mathrm{kA}$ with $0.1 \%$ precision [37].

The second one converts the voltage received from the PV module into a small voltage image. A simple resistive voltage divider circuit was used to lower the PV module voltage to an acceptable level. This resistive voltage divider was followed by a filter and an adaptation circuit connected to the ADC input of the microcontroller.

2.3.2. Embedded Microcontroller. This system uses LM3S1968 chip which belongs to ARM Cortex M3 family [38] whose frequency may be up to $80 \mathrm{Mhz}$, with 32 bit data bus. It contains serial interface peripherals, motion control peripherals, analogue peripherals and general purpose $I / O$ ports. In addition to the peripherals, it also has a 256 Kbyte flash memory for embedding user program codes and 96 Kbyte static RAM for storing high rate user data.

In this project, synchronous serial interface (SSI) peripheral was used to connect OLED graphics display with $128 \times$ 96 pixel resolution [39]. Analogue peripherals contain 10-bit ADCs in four channels. Two of them were used to digitize current and voltage data. Four navigation switches and one select pushbutton were connected to the general purpose $I / O$ ports for selection of shape of the leaf.

The real-time operating system that is embedded in the microcontroller code memory is powerful, which can 


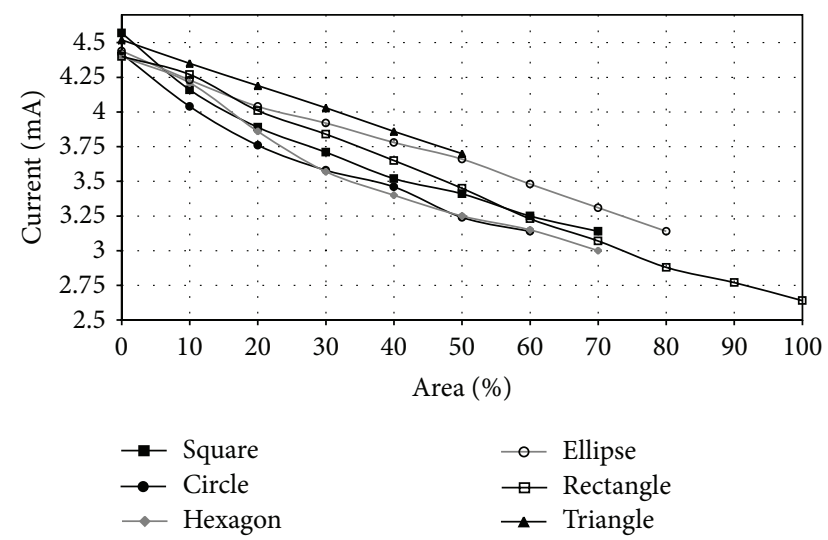

FIGURE 4: Comparison of current values obtained for semitransparent areas on light source.

measure current and voltage values then calculate leaf area according to user selected leaf shape and display the result in real time. Meanwhile, it can store all of the current, voltage, and measured leaf area values in data memory for later requests. Also the data may be uploaded to the computer using USB interface in real time or later whenever user needs. The operation is so easy and user-friendly.

\section{Results}

In this work of leaf area measurement with solar module, taking into consideration that the leaves to be measured could be of various dimensions, geometric shapes, and transparency, six different geometric shaped opaque carton and semitransparent white papers were used to shadow the solar module. Solar module surface area was shadowed from $10 \%$ to at most $100 \%$, resulting in a variation of the incoming radiation amount on the solar module's surface.

Solar module's short circuit current and open circuit voltage values due to the changes in radiation were measured for semitransparent areas and for opaque areas. The result of the partial shadowing on the solar module which is composed of series connected cells revealed that the area measurements using these six areas with different geometric shapes had dissimilar area-current and area-voltage relations.

On these results, incoming light amount from the PL lamp was altered by these areas and current and voltage measurements were made. The solar module was shadowed by square, circle, hexagon, triangle, ellipse, and rectangular shaped sample areas made of semitransparent and opaque materials, and the resulting graphs of area-current and areavoltage measurements are shown in Figures 4, 5, 6, and 7, respectively.

For the resulting measured values obtained by shadowing on the light source that are plotted in Figures 4, 5, 6 and 7 , regression curves are plotted and equations are calculated whereas a mathematical relation is obtained for area with respect to the solar module's short circuit current. The equation obtained for opaque rectangle areas' diagram is given in (4). Using this linear equation, short circuit current

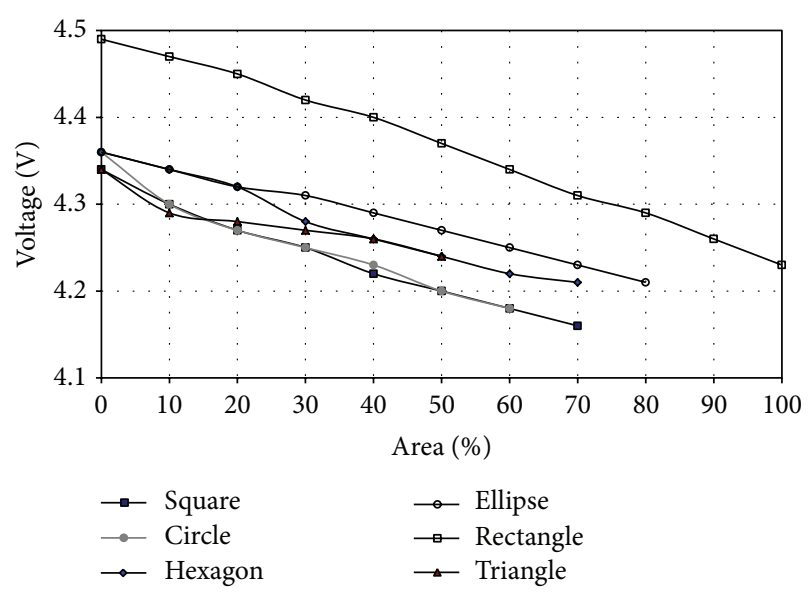

FIGURE 5: Comparison of voltage values obtained for semitransparent areas on light source.

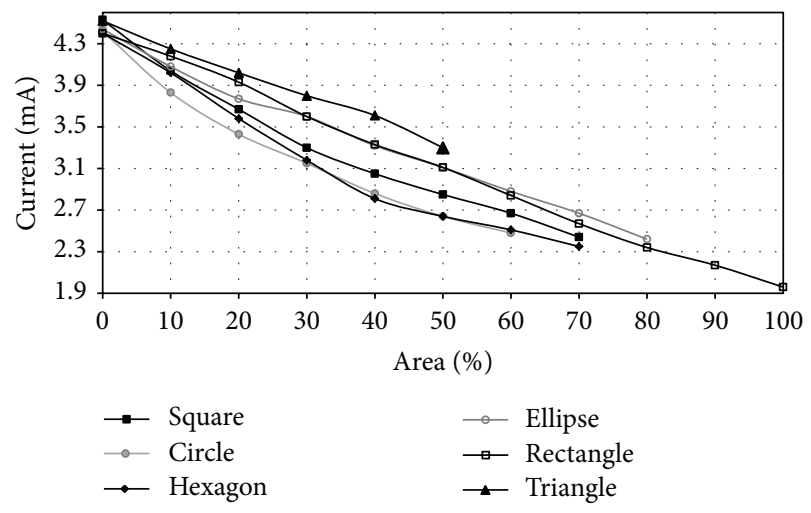

FIGURE 6: Comparison of current values obtained for opaque areas on light source.

values varying with area is calculated and given in Table 1 for comparison with the measured values:

$$
I_{\mathrm{sc}}=-0.0251 A+4.3327, \quad R^{2}=0.9965,
$$

where $I_{\mathrm{sc}}$ is short circuit current $(\mathrm{mA}), A$ is shadowing area (\%), and $R^{2}$ is regression coefficient.

As the measured values for ellipse areas are approximately equal to the ones obtained for rectangular areas, the values computed using a similar correlation as in (5) are given in the same table:

$$
I_{\mathrm{sc}}=-0.0243 A+4.3376, \quad R^{2}=0.994 \text {. }
$$

The computed $A-I_{\text {sc }}$ relationship for opaque isosceles triangle area is given by (6). Calculated values and measured values according to this equation are in Table 1 :

$$
I_{\mathrm{sc}}=-0.0235 A+4.5052, \quad R^{2}=0.9961 \text {. }
$$

Accordingly, area-short circuit current correlation for opaque hexagonal and circular areas is given in (5) and (6), respectively. As the area-current curves in Figure 6 for 
TABLE 1: Measured and obtained values for rectangle, ellipse, and triangle shaped areas indicating the relation between area and short circuit current of solar module.

\begin{tabular}{|c|c|c|c|c|c|c|}
\hline \multirow{2}{*}{$\begin{array}{l}\text { Area } \\
(\%)\end{array}$} & \multicolumn{2}{|c|}{ Rectangle, $I_{\mathrm{sc}}(\mathrm{mA})$} & \multicolumn{2}{|c|}{ Ellipse, $I_{\mathrm{sc}}(\mathrm{mA})$} & \multicolumn{2}{|c|}{ Triangle $I_{\mathrm{sc}}(\mathrm{mA})$} \\
\hline & Calculated & Measured & Calculated & Measured & Calculated & Measured \\
\hline 0 & 4.383 & 4.40 & 4.338 & 4.44 & 4.505 & 4.52 \\
\hline 10 & 4.132 & 4.18 & 4.095 & 4.08 & 4.270 & 4.25 \\
\hline 20 & 3.881 & 3.93 & 3.852 & 3.77 & 4.035 & 4.02 \\
\hline 30 & 3.630 & 3.60 & 3.609 & 3.60 & 3.800 & 3.80 \\
\hline 40 & 3.379 & 3.33 & 3.366 & 3.32 & 3.565 & 3.61 \\
\hline 50 & 3.128 & 3.11 & 3.123 & 3.11 & 3.330 & 3.30 \\
\hline 60 & 2.877 & 2.84 & 2.880 & 2.88 & - & - \\
\hline 70 & 2.626 & 2.57 & 2.637 & 2.67 & - & - \\
\hline 80 & 2.375 & 2.34 & 2.394 & 2.42 & - & - \\
\hline 90 & 2.124 & 2.17 & - & - & - & - \\
\hline 100 & 1.873 & 1.960 & - & - & - & - \\
\hline
\end{tabular}

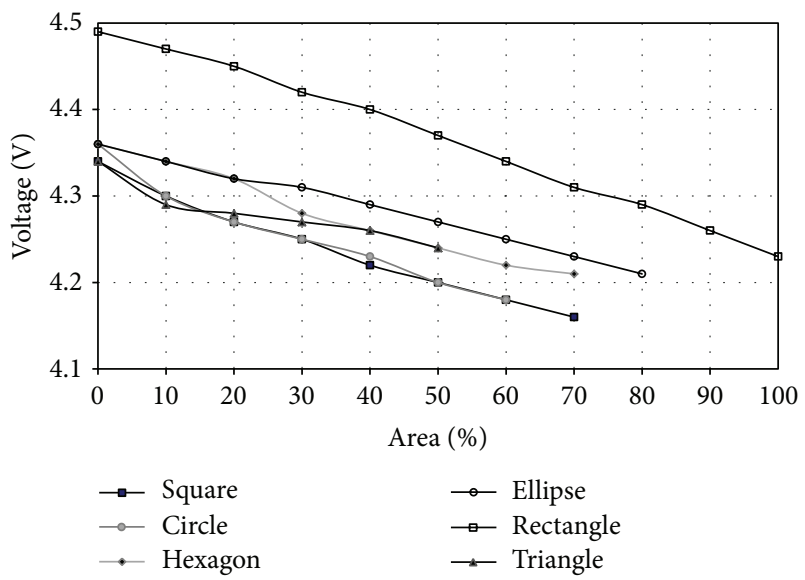

FIGURE 7: Comparison of voltage values obtained for opaque areas on light source.

TABLE 2: Measured and obtained values for hexagon and circle shape areas indicating the relation between area and short circuit current of solar module.

\begin{tabular}{lcccc}
\hline $\begin{array}{l}\text { Area } \\
(\%)\end{array}$ & \multicolumn{2}{c}{ Hexagon $I_{\text {sc }}(\mathrm{mA})$} & \multicolumn{2}{c}{ Circle, $I_{\mathrm{sc}}(\mathrm{mA})$} \\
Calculated & Measured & Calculated & Measured \\
\hline 0 & 4.447 & 4.40 & 4.379 & 4.42 \\
10 & 3.963 & 4.02 & 3.889 & 3.83 \\
20 & 3.539 & 3.58 & 3.479 & 3.43 \\
30 & 3.175 & 3.18 & 3.149 & 3.15 \\
40 & 2.871 & 2.81 & 2.899 & 2.86 \\
50 & 2.627 & 2.64 & 2.729 & 2.64 \\
60 & 2.443 & 2.51 & 2.639 & 2.48 \\
70 & 2.319 & 2.35 & - & - \\
80 & - & - & - & - \\
90 & - & - & - & - \\
100 & - & - & - & - \\
\hline
\end{tabular}

hexagonal and circular areas are observed, linearity error is more as compared to the other geometric shapes.
TABLE 3: Comparing grid counting method with developed leaf area meter.

\begin{tabular}{lccc}
\hline Sample & Grid counting $^{1}$ & Leaf area meter & Difference \\
\hline 1 & $1653 \mathrm{~mm}^{2}$ & $1648 \mathrm{~mm}^{2}$ & $5 \mathrm{~mm}^{2}$ \\
2 & $2008 \mathrm{~mm}^{2}$ & $2126 \mathrm{~mm}^{2}$ & $-118 \mathrm{~mm}^{2}$ \\
3 & $1746 \mathrm{~mm}^{2}$ & $1794 \mathrm{~mm}^{2}$ & $-52 \mathrm{~mm}^{2}$ \\
4 & $578 \mathrm{~mm}^{2}$ & $572 \mathrm{~mm}^{2}$ & $6 \mathrm{~mm}^{2}$ \\
\hline
\end{tabular}

${ }^{1}$ Millimeter graph paper method.

${ }^{2}$ Developed leaf area meter.

Consequently, when the areas of leaves in similar forms of hexagonal and circular geometric shapes are to be measured, a second order polynomial trend line should be obtained and equations are estimated as in (7) and (8). For comparison with the other measurements, the calculated values using these equations are also given in Table 2 allied with measured values:

$$
\begin{array}{ll}
I_{\mathrm{sc}}=0.0003 A^{2}-0.0514 A+4.4471, & R^{2}=0.9965, \\
I_{\mathrm{sc}}=0.0004 A^{2}-0.053 A+4.3786, & R^{2}=0.9972 .
\end{array}
$$

PV module's current and voltage changes resulting in shadowing of the leaf was measured using current and voltage sensors, and these signals were provided for the microcontroller inputs through signal conditioning circuits. The measurement of a sample leaf, which was placed in between the PV module and a diffusing glass, using the developed area meter is shown in Figure 8. The shape of the leaf which resembles to one of the tested areas is selected by the switches. According to the obtained equations, the microcontroller program calculated the leaf area and this leaf area was displayed on an OLED as shown in Figure 9. The leaves tested by the area meter are shown in Figure 10.

The measured areas by the area meter were then compared with the ones obtained from the millimeter graph paper method. The evaluation of the developed method is given in Table 3 .

When the geometric shape is similar to one of the regular geometric shapes that were tested by the leaf area meter, the 


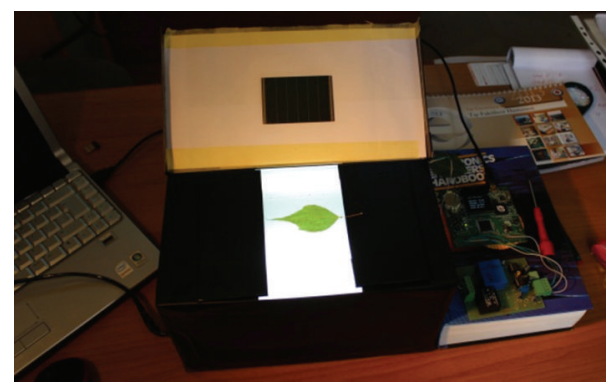

FIgURE 8: Placement of sample leaf.

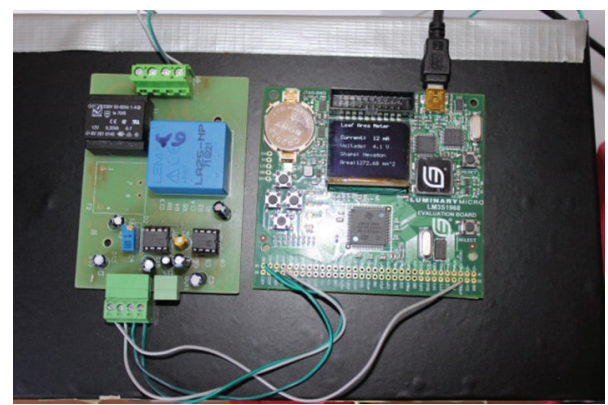

Figure 9: Sample leaf area measurement.

error is about $\pm 1 \%$, but irregular shaped leaves contribute to an error of at most $\pm 5 \%$.

\section{Discussion}

In this study, shadowing was first performed on the solar module; however partial shadowing of solar module with series connected cells resulted in different area-current and area-voltage variations for each different geometric shape. The same areas are represented by different current and voltage values for different geometric shapes. Shadowing of one of the series connected cells completely or more than the others decreases the cell current and consequently the solar module's output current and thus results in a sudden decline in shadowing-current relationship. This outcome of partial shadowing effect on series connected cells were observed by making current and voltage measurements; thus it was concluded that this method of procedure could not be an appropriate approach for leaf area measurement.

On the intent of overcoming the partial shadowing effect, instead of shadowing on the solar module, sample areas were placed on the light source by varying the light amount on the solar module, and the same area measurements were repeated. The resulting area-current and area-voltage curves (Figures 4, 5, 6, and 7) were observed, and it was concluded that by shadowing on the light source, partial shadowing effects were diminished and the variation in the solar module's current with area changes were linear with a regression coefficient, $R^{2}>0.99$, and it is concluded that this leaf area measuring setup can be a convenient prototype.

It is also observed that the geometric shape of the leaf is an important factor. The form of the leaf whose area to be

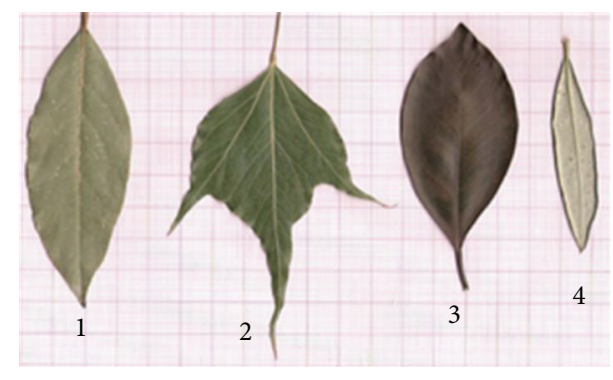

FIgURE 10: Leaf samples.

measured should be determined according to the plots and equations of the geometric shape that it fits. Another factor is the transparency of the leaf and this changes the light amount received by the solar module. To neutralize this transparency effect, leaf is to be molded by an opaque material such as carton, and it is suggested that this prepared area should be measured.

The open-circuit voltage and the short-circuit current obtained from the PV module were then fed to an ARM Cortex M3 core 32-bit microcontroller via a voltage and current measuring unit which includes voltage and current sensors, amplification and attenuation circuit, and a noise reduction filter. The analogue voltage and current signals were converted to digital form by means of ADC inputs of the microcontroller. The obtained equations relating the area with the short-circuit current of the PV module were used in the microcontroller program and displayed on an OLED. For more accurate area measurements, regarding each geometric shape, the calculated shape factor was selected by four navigation switches and one select pushbutton which were connected to the general purpose $I / O$ ports.

In this work, thin-film solar module with 6 series connected cells was used. During the first trial, the partial shadowing problem that had come up was overcome by shadowing on the light source. In order to deal with the partial shadowing problem, a single monocrystal silicon solar cell is recommended for area measurements instead of using a solar module consisting series connected cells.

It is also recommended that two leaves should be used for area measurement, and one of them is to be cut from $10 \%$ to $100 \%$ of solar module's area and with these reference areas current measurements should be made. Consequently, the obtained area-current graph and equation are used for measurement of other leaf's area. In this method, leaf area's geometric shape and transparency percentage is no longer important. This method would be more practical in case that the areas of the same variety leaves are recurrently measured.

\section{Conclusions}

Leaf area is an important index in plant growth study and in prediction of the product of crop. Various methods as square grid counting and gravimetric and pixel counting using image processing are mostly used for leaf area measurements. On the other hand, when dealing with a large number of leaves, 
these approaches turn out to be laborious and time consuming. A solar cell based method for leaf area measurement was developed and implemented. In this system, the shadowing effect by the plant leaf on the solar cell was used. The system has two $7 * 10 \mathrm{~cm}^{2}$ and $5 * 7 \mathrm{~cm}^{2}$ amorphous silicon solar modules which were composed of 6 series connected cells, an $11 \mathrm{~W}$ PL lamp, a stainless steel parabolic reflector for reflecting the light from the light source to the solar module in parallel, an opal glass used for diffusing the parallel reflected light, and a case for housing these components. Different geometric shaped areas were used to simulate the leaves having various shapes. The current and voltage values were measured due to shadowing effect of these areas to be evaluated. The resulting voltage and current measurements were then fed to an ARM Cortex M3 core 32-bit LM3S1968 microcontroller via a voltage and current measuring unit. The calculated leaf areas from the obtained area-current relations were shown on an OLED graphics display. The whole system is easy to use and user-friendly. The achieved results are compared with the measured areas by grid counting method. Different species of leaves are tested by the leaf area meter. Experimental results show that this developed method contributes to a result that is reasonable to be used as a leaf area meter. Accuracy of this method is found to be about $\pm 99 \%$ for regular shaped leaves where accuracy is $\pm 95 \%$ for irregularly shaped leaves. The leaf area measurements are confirmed by comparing the results with measurements of grid counting method.

\section{References}

[1] S. Pandey and H. Singh, "A simple cost-effective method for leaf area estimation," Journal of Botany, vol. 2011, Article ID 658240, 6 pages, 2011.

[2] D. Wulfsohn, M. Sciortino, J. M. Aaslyng, and M. GarcíaFiñana, "Nondestructive, stereological estimation of canopy surface area," Biometrics, vol. 66, no. 1, pp. 159-168, 2010.

[3] E. Mendoza-de Gyves, V. Cristofori, C. Fallovo, Y. Rouphael, and C. Bignami, "Accurate and rapid technique for leaf area measurement in medlar (Mespilus germanica L.)," Advances in Horticultural Science, vol. 22, no. 3, pp. 223-226, 2008.

[4] J. Diao, X. Lei, L. Hong, J. Rong, and Q. Shi, "Estimating single leaf area of Eucalyptus (Eucalyptus grandis $\times$ Eucalyptus urophylla) using leaf length and width," in Proceedings of the $3 r d$ International Symposium on Plant Growth Modeling, Simulation, Visualization and Applications (PMA '09), pp. 53-57, November 2009.

[5] F. Giuffrida, Y. Rouphael, S. Toscano et al., "A simple model for nondestructive leaf area estimation in bedding plants," Photosynthetica, vol. 49, no. 3, pp. 380-388, 2011.

[6] L. S. Caldas, C. Bravo, H. Piccolo, and C. R. Faria, "Measurement of leaf area with a hand-scanner linked to a microcomputer," Revista Brasileira de Fisiologia Vegetal, vol. 4, no. 1, pp. 17-20, 1992.

[7] C. Igathinathane, V. S. S. Prakash, U. Padma, G. R. Babu, and A. R. Womac, "Interactive computer software development for leaf area measurement," Computers and Electronics in Agriculture, vol. 51, no. 1-2, pp. 1-16, 2006.

[8] Y. Murata and K. Hayashi, "On a new, automatic device for leafarea-measurement," Proceedings of the Crop Science Society of Japan, vol. 36, pp. 463-467, 1967.
[9] M. Tsuda, "Errors in leaf area measurement with an automatic area meter due to leaf chlorophyll in crop plants," Annals of Botany, vol. 84, no. 6, pp. 799-801, 1999.

[10] M. Fladung and E. Ritter, "Plant leaf area measurements by personal computers," Journal of Agronomy and Crop Science, vol. 166, no. 1, pp. 69-70, 1991.

[11] A. Jia and S. Zhang, "Processing of leaf area measurement using digital photographic image based on matlab," Journal of Shanxi Agricultural University (Natural Science Edition), vol. 1, pp. 8082, 2006.

[12] T. Feng and W. Chun, "Calculating the leaf-area based on nonloss correction algorithm," in Proceedings of the International Conference of Information Science and Management Engineering (ISME '10), pp. 75-78, August 2010.

[13] H. Hajjdiab and A. Obaid, "A vision-based approach for nondestructive leaf area estimation," in Proceedings of the 2nd Conference on Environmental Science and Information Application Technology (ESIAT '10), pp. 53-56, July 2010.

[14] Q. Tian, Z. Cao, and R. Zhang, "Digital camera and Auto CAD based method for measuring the leaf area of landscape plants," Grassland and Turf, vol. 3, pp. 25-28, 2008.

[15] C. Bin and L. Boyou, "The photoelectric leaf area measurement system based on MCU," Journal of Agricultural Mechanization Research, 2010.

[16] T. Youwen and W. Xiaojuan, "Design of hand-held leaf area meter based on ARM9," Journal of Agricultural Mechanization Research, 2009.

[17] L. Zhang and X.-S. Liu, "Non-destructive leaf-area estimation for Bergenia purpurascens across timberline ecotone, southeast Tibet," Annales Botanici Fennici, vol. 47, no. 5, pp. 346-352, 2010.

[18] D. H. Park, H. J. Kang, and S. H. Kim, "A study on image processing based leaf area measurement," Future Information Technology, Application, and Service, vol. 179, pp. 97-102, 2012.

[19] E. Rico-García, F. Hernández-Hernández, G. M. Soto-Zarazúa, and G. Herrera-Ruiz, "Two new methods for the estimation of leaf area using digital photography," International Journal of Agriculture and Biology, vol. 11, no. 4, pp. 397-400, 2009.

[20] M. Marcon, K. Mariano, R. A. Braga, C. M. Paglis, M. S. Scalco, and G. W. Horgan, "Estimation of total leaf area in perennial plants using image analysis," Revista Brasileira de Engenharia Agricola e Ambiental, vol. 15, no. 1, pp. 96-101, 2011.

[21] C. Igathinathane, B. Chennakesavulu, K. Manohar, A. R. Womac, and L. O. Pordesimo, "Photovoltaic leaf area meter development and testing," International Journal of Food Properties, vol. 11, no. 1, pp. 53-67, 2008.

[22] K. Kirk, H. J. Andersen, A. G. Thomsen, J. R. Jørgensen, and R. $\mathrm{N}$. Jørgensen, "Estimation of leaf area index in cereal crops using red-green images," Biosystems Engineering, vol. 104, no. 3, pp. 308-317, 2009.

[23] Y. Tian and X. Wang, "Development of hand-held leaf area meter based on S3C2440," in Proceedings of the 9th International Conference on Electronic Measurement and Instruments (ICEMI '09), pp. 2571-2575, IEEE, August 2009.

[24] Florida Solar Energy Center, Installing Photovoltaic Systems. A Question and Answer Guide For Solar Electric Systems, 1999.

[25] A. D. Hansen, P. S. Sørensen, L. H. Hansen, and H. Bindner, Models for a Stand-Alone PV System, Risø National Laboratory, 2000.

[26] T. Markvart and L. Castañer, Practical Handbook of Photovoltaics Fundamentals and Applications, Elsevier, New York, NY, USA, 2003. 
[27] S. Rustemli and F. Dincer, "Modeling of photovoltaic panel and examining effects of temperature in Matlab/Simulink," Elektronika ir Elektrotechnika, vol. 109, no. 3, pp. 35-40, 2011.

[28] PHILIPS, PL-S 11W/10/2P 1CT lamp. 2012, http://www.ecat .lighting.philips.com/l/lamps/uv/fluorescent-specialties/actinic-bl-pl-s-pl-1/927902321007_eu/.

[29] J. Feldman, S. Singer, and A. Braunsten, "Solar cell interconnections and the shadow problem," Solar Energy, vol. 26, no. 5, pp. 419-428, 1981.

[30] N. D. Kaushika and N. K. Gautam, "Energy yield simulations of interconnected solar PV arrays," IEEE Transactions on Energy Conversion, vol. 18, no. 1, pp. 127-134, 2003.

[31] R. Kadri, H. Andrei, J.-P. Gaubert, T. Ivanovici, G. C. Gérard Champenois, and P. Andrei, "Modeling of the photovoltaic cell circuit parameters for optimum connection model and realtime emulator with partial shadow conditions," Energy, vol. 42, no. 1, pp. 57-67, 2011.

[32] L. A. Hecktheuer, A. Krenzinger, and C. W. M. Prieb, "Methodology for photovoltaic modules characterization and shading effects analysis," Journal of the Brazilian Society of Mechanical Sciences, vol. 24, no. 1, pp. 26-31, 2002.

[33] M. C. di Piazza and G. Vitale, "Photovoltaic field emulation including dynamic and partial shadow conditions," Applied Energy, vol. 87, no. 3, pp. 814-823, 2010.

[34] R. Ramaprabha and B. L. Mathur, "Modelling and simulation of solar pv array under partial shaded conditions," in Proceedings of the IEEE International Conference on Sustainable Energy Technologies (ICSET '08), pp. 7-11, November 2008.

[35] S. Guo, T. M. Walsh, A. G. Aberle, and M. Peters, "Analysing partial shading of PV modules by circuit modelling," in Proceedings of the 38th IEEE Photovoltaic Specialists Conference (PVSC '12), IEEE, 2012.

[36] LEM. Hall-effect current sensor, 2012, http://www.semikron .com/products/data/cur/assets/LA_25_NP_90_08_19_000_0_ 13950115.pdf.

[37] P. Ripka, "Electric current sensors: a review," Measurement Science and Technology, vol. 21, no. 11, Article ID 112001, 2010.

[38] TI. Stellaris LM3S811 Microcontroller, 2012, http://www.ti.com/ lit/ds/symlink/lm3s811.pdf.

[39] R. Display, “OLED Display," 2012, http://www.gamma.spb.ru/ download/P16807-A03.pdf. 

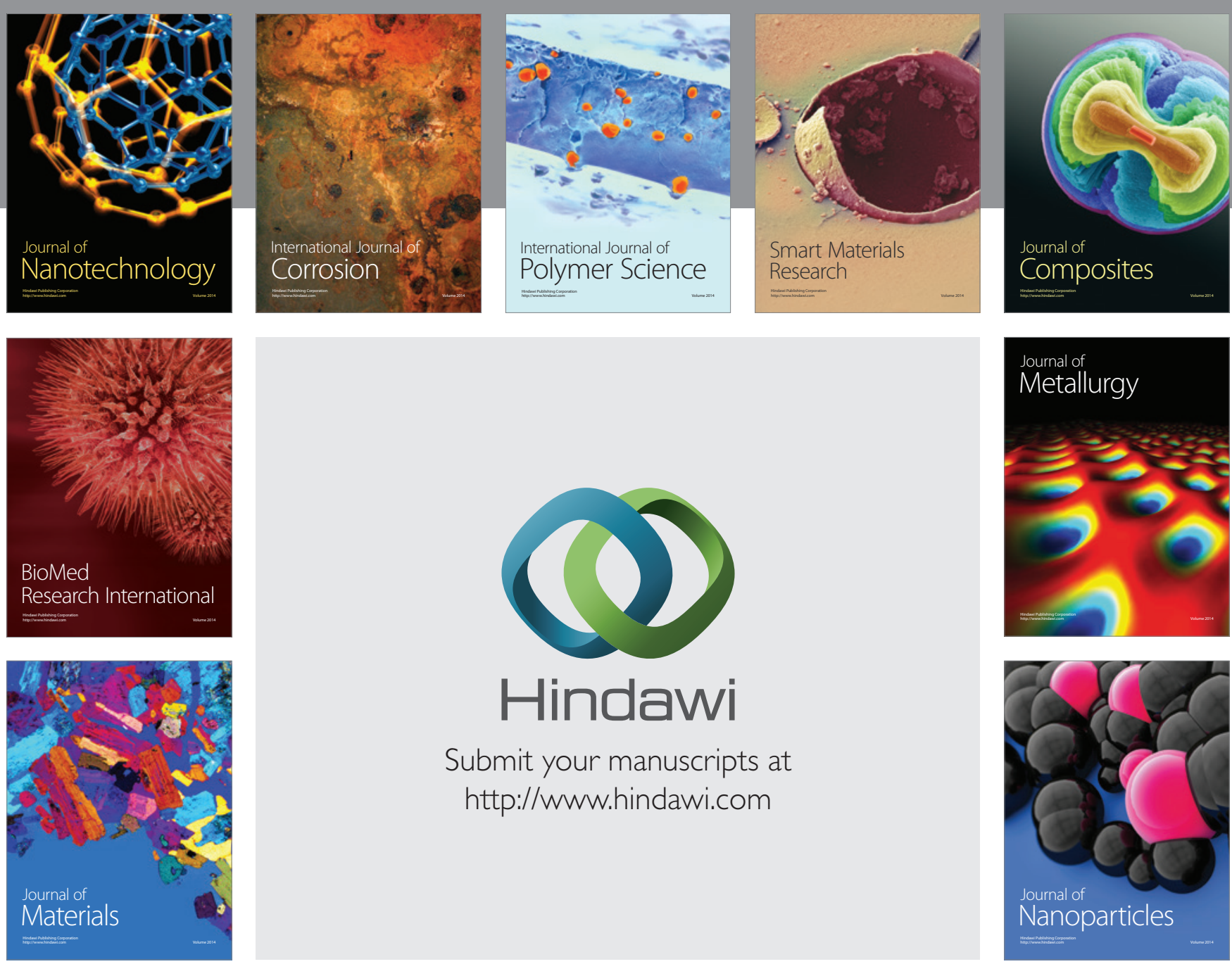

Submit your manuscripts at http://www.hindawi.com
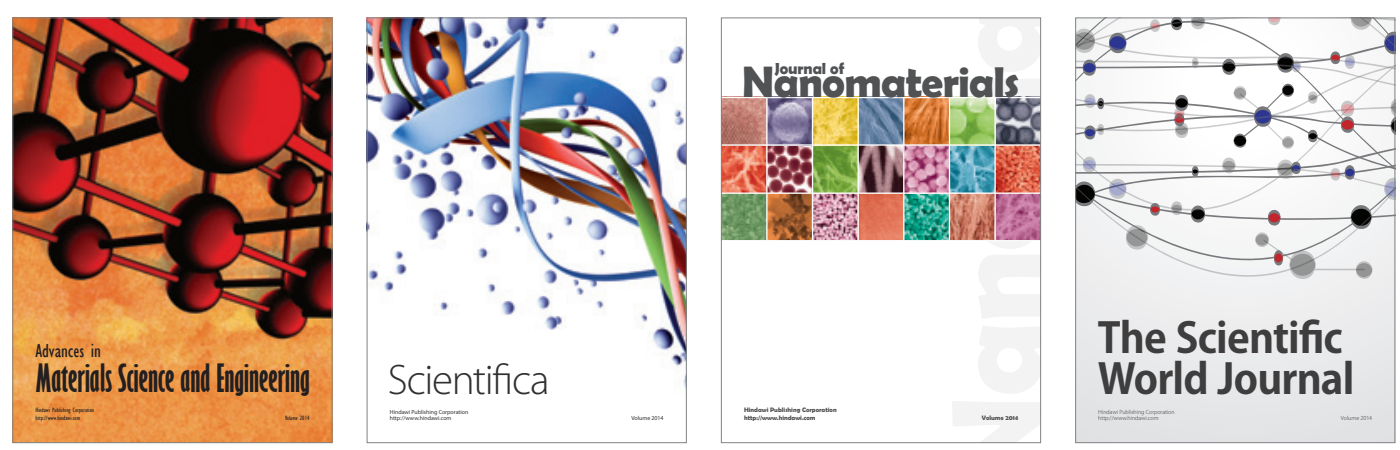

\section{The Scientific World Journal}
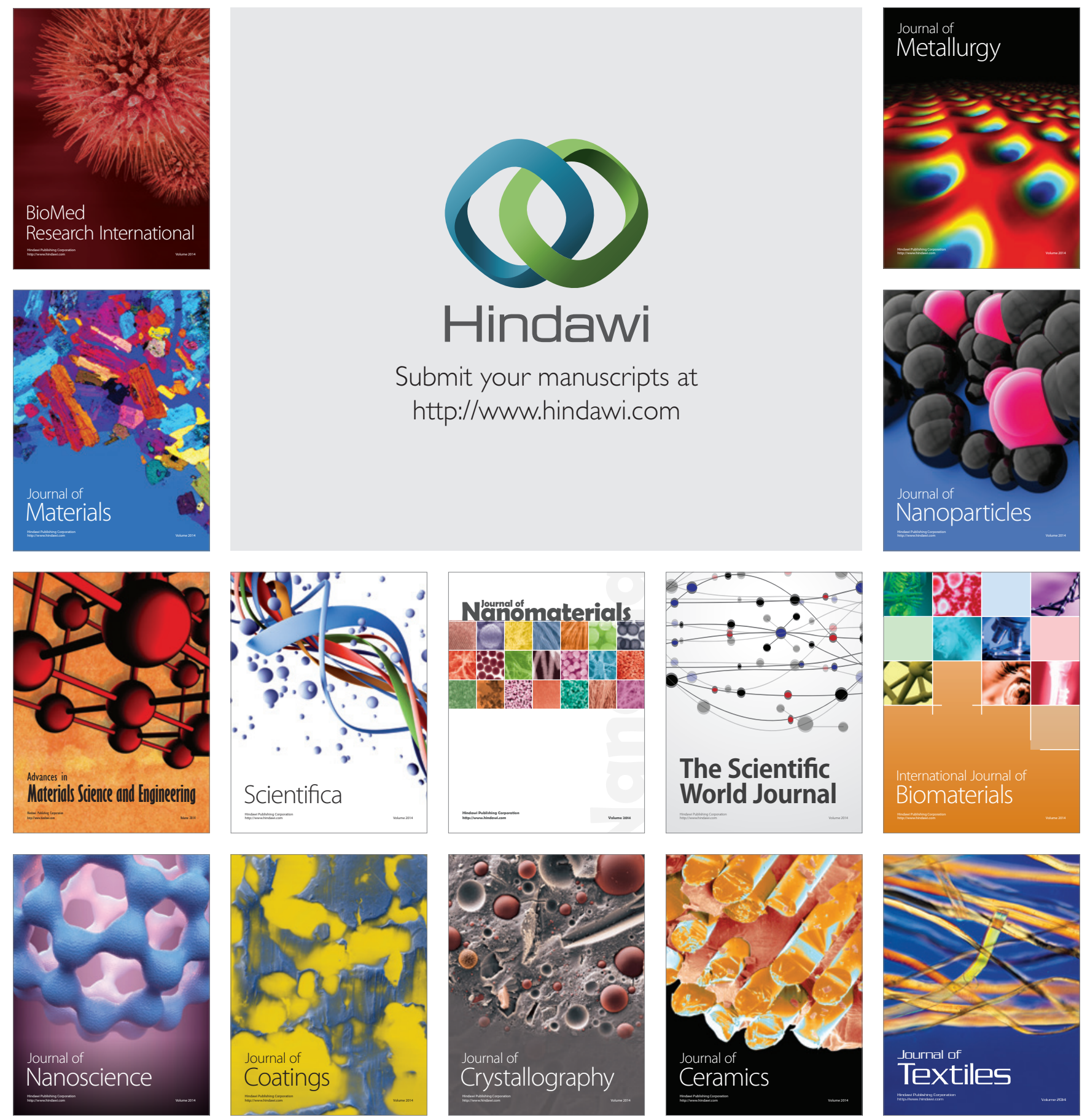